\title{
Role of $\mathrm{OH}$ variability in the stalling of the global atmospheric $\mathrm{CH}_{4}$ growth
} rate from 1999 to 2006

Joe McNorton et al.

Correspondence to: Joe McNorton (eejrm@leeds.ac.uk)

The copyright of individual parts of the supplement might differ from the CC-BY 3.0 licence. 


\section{Supplement S1: Global Box Model}

To investigate the overall impact of changes in temperature, $[\mathrm{OH}]$ and emissions on an atmospheric gas which is removed by $\mathrm{OH}$ a simple global box model can be used. This model permits a first-order understanding of the factors which govern the variation in growth and the relative contribution of emissions and loss to that growth. The model integrates the global mean burden of $\mathrm{X}(\mathrm{Tg})$ based on annual mean emissions $(E, \mathrm{Tg} / \mathrm{yr})$ and chemical loss $(L, \mathrm{Tg} / \mathrm{yr})$ through the reaction $\mathrm{X}+\mathrm{OH} \rightarrow$ products. The modelled atmospheric burden of $\mathrm{X}(\mathrm{X}, \mathrm{t})$ can be integrated over a 1-year period $(\Delta t)$ according to the equation:

$$
\frac{1}{\Delta t}\left(X_{t+\Delta t}-X_{t}\right)=E-L=E-k[O H][X]
$$

where $k\left(\mathrm{~cm}^{3}\right.$ molecule $\left.\mathrm{yr}^{-1}\right)$ is the rate constant for the $\mathrm{X}+\mathrm{OH}$ reaction (e.g. Sander et al., 2011). For $\mathrm{CH}_{4} k=2.45 \times 10^{-12} \exp (-1775 / \mathrm{T})$ while for $\mathrm{CH}_{3} \mathrm{CCl}_{3} k=1.64 \times 10^{-12} \exp (-1520 / \mathrm{T})$.

When simulating $\mathrm{CH}_{3} \mathrm{CCl}_{3}$ we assume emissions from Montzka et al. (2011) or Rigby et al. (2013) and $T=272.9 \mathrm{~K}$. We then use equation (1) to derive the global mean [OH] which is consistent with the observed variations in $\mathrm{CH}_{3} \mathrm{CCl}_{3}$. The same procedure is used to derive global mean $[\mathrm{OH}]$ consistent with the observed $\mathrm{CH}_{4}$ variations assuming $E=553 \mathrm{Tg} / \mathrm{yr}$.

\section{Supplement S2: Spatial differences between $\mathrm{CH}_{4}$ and $\mathrm{CH}_{3} \mathrm{CCl}_{3}$}

As noted in Section 3.2.2 of the main text, anomalies in global $\mathrm{OH}$ derived from global $\mathrm{CH}_{3} \mathrm{CCl}_{3}$ variations might not be appropriate when considering changes in global $\mathrm{CH}_{4}$. This is based on the fact that the same $\mathrm{OH}$ anomalies produce a different response when applied to $\mathrm{CH}_{4}$ and $\mathrm{CH}_{3} \mathrm{CCl}_{3}$ in the model with and without the effect of wind and temperature variability (see Figures 2 and $5 \mathrm{a}$ of the main text).

To investigate the possible impact of the distribution of sites used to derive the $\mathrm{OH}$ variations, we compare the modelled growth rate of global $\mathrm{CH}_{4}$, derived from model sampling at NOAA and $\mathrm{AGAGE} \mathrm{CH}_{4}$ sites, with the modelled decay rate anomaly of $\mathrm{CH}_{3} \mathrm{CCl}_{3}$, derived from model sampling at NOAA and $\mathrm{AGAGE} \mathrm{CH}_{3} \mathrm{CCl}_{3}$ sites (Figure $\mathrm{S} 1$ ). The results show that, despite the spatial differences between the sampled locations, the $\mathrm{CH}_{3} \mathrm{CCl}_{3}$ decay rate anomaly correlates well (negatively) with the $\mathrm{CH}_{4}$ growth rate, in agreement with the observations (see Figure 1a of main text).

After $1997 \mathrm{CH}_{3} \mathrm{CCl}_{3}$ emissions diminish and the atmospheric concentration becomes spatially uniform. Site sampling of the $\mathrm{CH}_{3} \mathrm{CCl}_{3}$ decay rate anomaly after 1997 should therefore accurately represent global decay. For $\mathrm{CH}_{4}$ the emission sources influence the spatial distribution of the atmospheric concentration and therefore the loss rate due to $\mathrm{OH}$ (Figure $\mathrm{S} 2$ ). In addition, for this reason variability in transport is more likely to influence the global growth rate of $\mathrm{CH}_{4}$ than the decay rate anomaly of $\mathrm{CH}_{3} \mathrm{CCl}_{3}$ (see main text). 

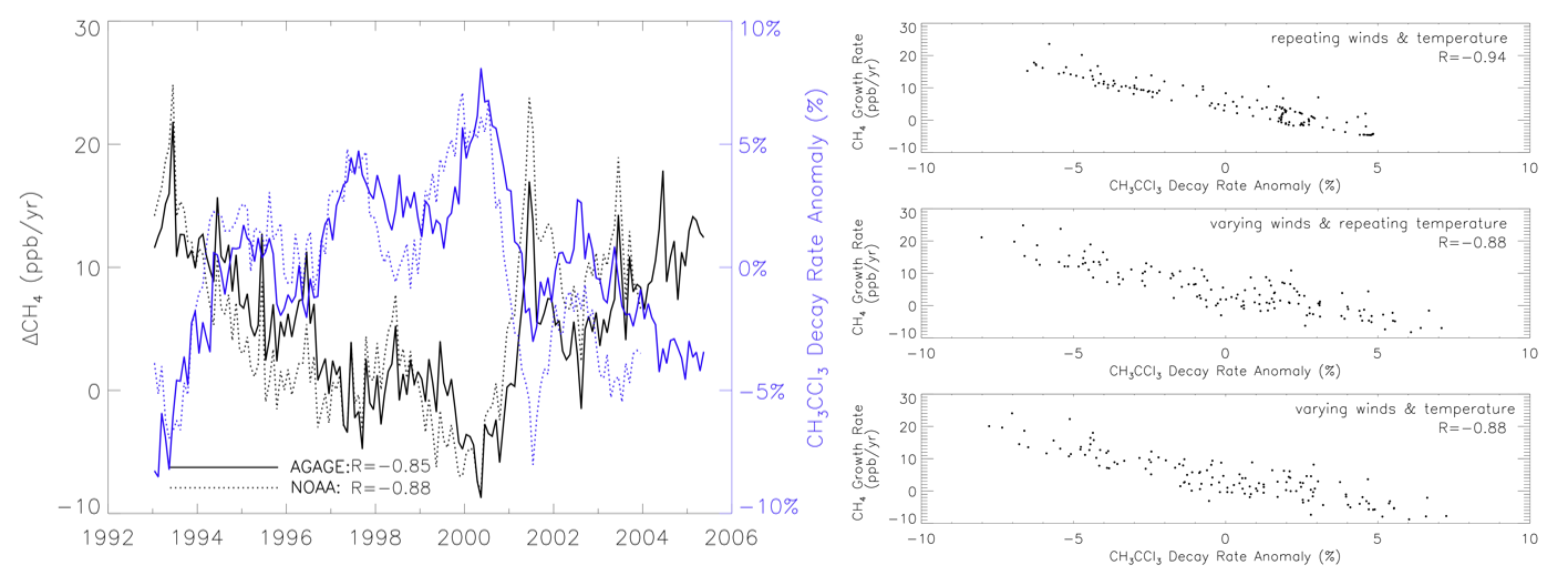

Figure S1. (Left) The smoothed variation in global annual $\mathrm{CH}_{4}$ growth rate (ppb/yr) derived from TOMCAT 3-D CTM sampled at NOAA (black solid) and AGAGE (black dashed) $\mathrm{CH}_{4}$ site locations (left axis). Also shown are the smoothed global $\mathrm{CH}_{3} \mathrm{CCl}_{3}$ decay rate anomalies derived from TOMCAT sampled at NOAA and AGAGE $\mathrm{CH}_{3} \mathrm{CCl}_{3}$ site locations (right axis). The legend gives represent correlation coefficients of global model $\mathrm{CH}_{4}$ growth rate compared with the $\mathrm{CH}_{3} \mathrm{CCl}_{3}$ decay rate anomaly for AGAGE and NOAA locations. (Right) Correlation plots for global $\mathrm{CH}_{4}$ growth rate and $\mathrm{CH}_{3} \mathrm{CCl}_{3}$ decay rate anomalies, sampled at respective locations, from the TOMCAT simulation which uses NOAA-derived $\mathrm{OH}$ anomalies and, (top) repeating winds and temperature, (middle) varying winds and repeating temperature and (bottom) varying winds and temperature. 

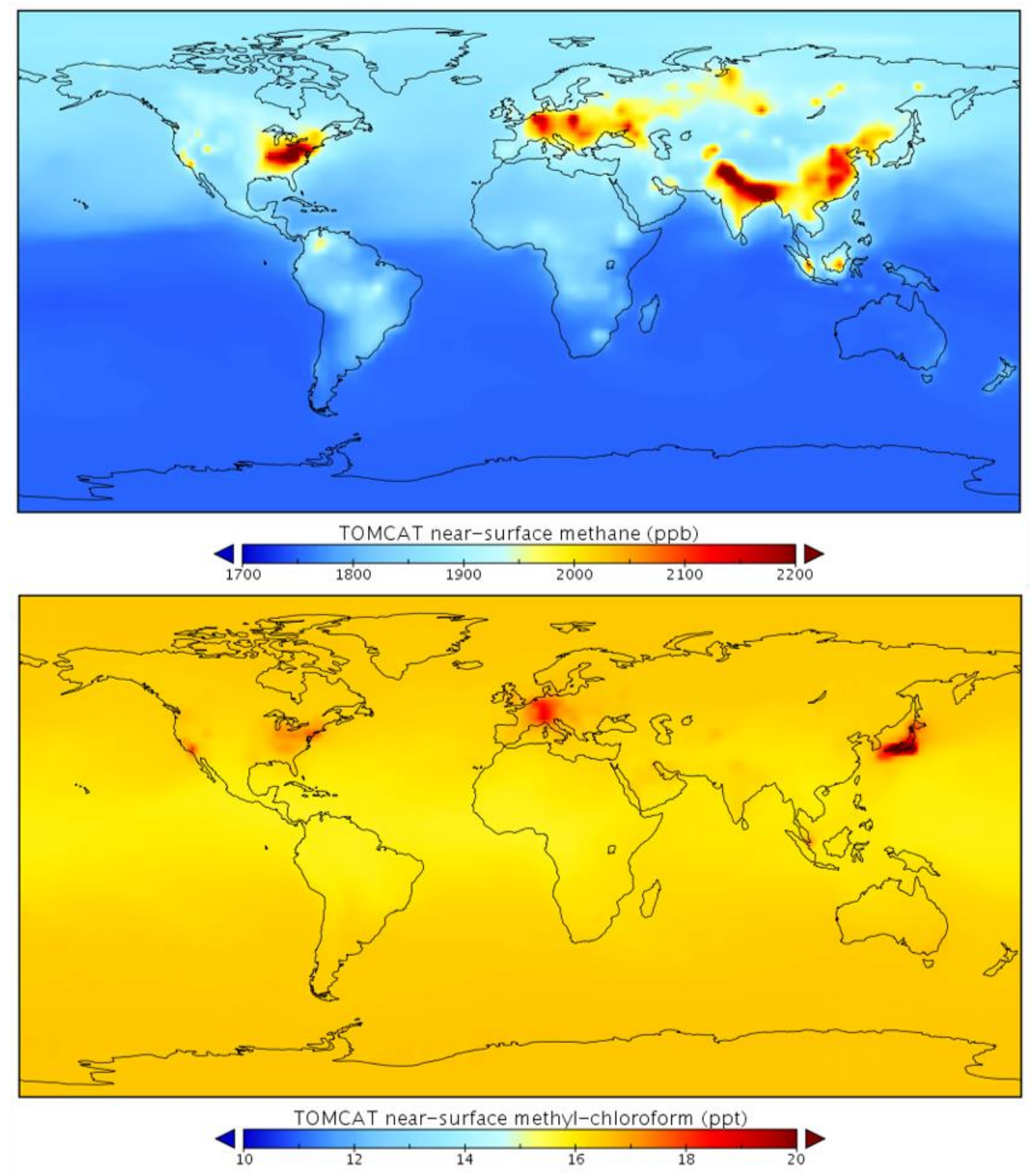

Figure S2. Monthly mean distribution of near surface (top) $\mathrm{CH}_{4}$ (ppb) and (bottom) $\mathrm{CH}_{3} \mathrm{CCl}_{3}$ (ppt) for September 2005 from a TOMCAT simulation. 